\title{
The role of families and providers in preventing childhood obesity when we take a systems approach to ending the epidemic
}

Sabina B. Gesell ${ }^{1}$, Sharon M. Karp ${ }^{2}$

1 Department of Social Sciences and Health Policy, Division of Public Health Sciences, Wake Forest University School of Medicine, Medical Center Boulevard, Winston-Salem, NC 27157, USA

2 Vanderbilt University, Schools of Nursing and Medicine (Pediatrics), Nashville, TN 37240, USA

\section{Introduction}

Obesity is now a global public health issue. According to the newest analysis by the International Obesity Task Force approximately 1.5 billion adults, 200 million school aged children, and 40 million children under the age of five are either overweight or obese [1]. This is twice the number of people who are suffering from famine, malnutrition, and starvation [2]. The US is the heaviest nation with over $60 \%$ of all adults and $30 \%$ of children overweight or obese [3,4]. The economic burden of obesity in the US alone is staggering. Direct and indirect medical care costs in the US related to obesity have been estimated to total $\$ 147$ billion dollars annually [5].

These alarming data give pause, and highlight the urgency to develop effective obesity prevention strategies. Without effective strategies to slow the development of childhood obesity and subsequent co-morbid conditions (i.e., diabetes), it is estimated that our current generation of young children will have not the life expectancy of their parents' generation [6]. Undeniably, tremendous resources have been dedicated to the obesity problem in the form of formal research interventions and community outreach programs - yet our interventions and programs generally fail and those that do show a measurable change are only modest in effect size, rarely replicated, and difficult to sustain. As a result, most of our efforts continue to be ineffective and we have not achieved a decrease in the obesity prevalence. This year the Institute of Medicine (IOM) evaluated progress made in implementing a wide range of obesity-prevention strategies and identified critical steps for the nation to accelerate progress in preventing obesity over the next decade [7]. The IOM's recommendations, when implemented together, could profoundly reshape the environments where people live, learn, work, and play. Notably, they do not place the onus on individuals but instead call for policy, system and environmental changes.

The multiple, non-linear, often time-delayed, bi-directional and counter-intuitive forces at the local, state and national levels that are sustaining the obesity epidemic are too complex to solve by manda- 
ting individual behavior change without concomitant system change [8-11]. In order to dramatically improve the public's health for generations to come, scientists and policy makers need to apply systems science methods to understand the obesity-sustaining forces acting on individuals, with focused attention on critical periods of development (i.e., preconception, prenatal, postpartum, early childhood).

\section{Shifting perspectives}

As a society, we need to shift our perspective of best times to intervene to maximize the health and well-being of our citizens. It is well established that childhood health care must begin before birth. This prenatal attention should be expanded to obesity prevention. Evidence from basic research, prevention research, and systems research suggest that intervening during and prior to pregnancy can have an a cross-generational effect on health [11].

A key element of the obesity epidemic is the vicious cycle of obese women producing offspring with a tendency to develop obesity, who then develop into obese adults and become obese parents themselves (Figure 1). Appropriate weight gain during pregnancy reinforces maternal health, as well as fetal health, and childhood health. However, approximately $45 \%$ of US women gain in excess of the clinical guidelines established by the IOM two decades ago $[12,13]$.

Ideally women will establish a healthy weight before conception; but because $50 \%$ of pregnancies are unplanned [14], it is initially more feasible to intervene during the 40 weeks of pregnancy and the first postpartum year. Greater gestational weight gain has been associated with greater offspring body mass index (BMI) in childhood, in adolescence and, most recently, in early adulthood [15-17]. This is thou-

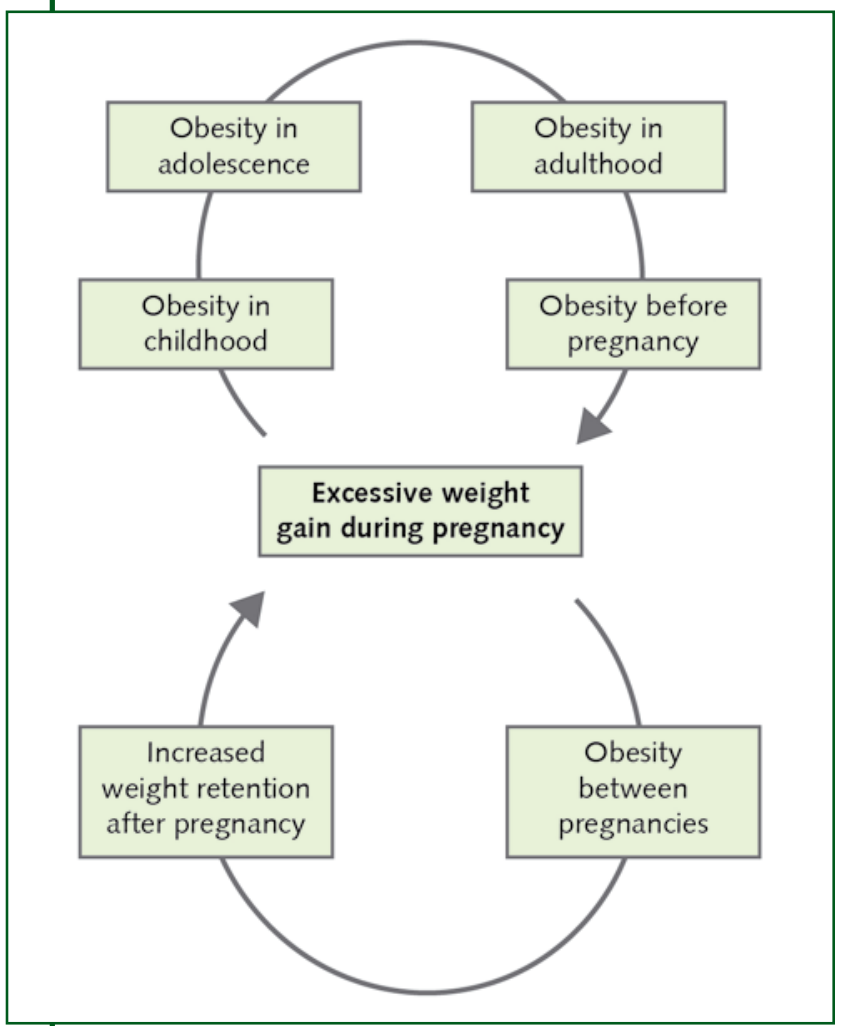

Figure 1. The intergenerational vicious cycle of obesity that begins with excessive weight gain during pregnancy ght to be due to developmental programming and over nutrition in utero [18-21], in addition to environmental exposure to the same obesogenic lifestyle as the mother [22-27]. Excessive gestational weight gain is also associated with excessive postpartum weight retention [28,29], which can exacerbate the cycle of maternal-infant health complications in subsequent pregnancies. Helping mothers avoid excessive weight gain during pregnancy and excessive weight retention postpartum may constitute unique opportunities for true prevention of childhood obesity.

Efforts to interrupt the cycle of maternal-infant health complications that begin with obesity in pregnancy can be derived by enabling mothers to act in accordance with IOM guidelines. Although behavior change is not easy to achieve, initiating preventative strategies around the time of pregnancy has resulted in sustained behavior change regarding other health decisions. For example, Cochrane reviews of interventions to reduce smoking and alcohol consumption during pregnancy demonstrated effectiveness in changing maternal health behaviors [30,31]. 
To date, existing interventions to prevent excessive weight gain are so limited in number and effectiveness, that both the IOM [32] and the Agency for Health care Research and Quality (AHRQ) [33] have identified this as a major research gap. Interventions based on physical activity and dietary counseling, usually combined with supplementary weight monitoring [34,35], have had modest success in reducing the amount of excessive weight gained during pregnancy, but few efforts have been effective enough for women to gain within their IOM target range [36,37].

Thus, we need to design effective interventions that prevent excessive weight gain during pregnancy that are widely effective, practical, cost-effective, and have mechanisms for widespread diffusion. We should conduct comparative effectiveness research comparing important public health interventions currently in place, such as different models of prenatal care (i.e., traditional individual prenatal care vs. group prenatal care), and the Special Supplemental Nutrition Program for Women, Infants and Children (WIC) Program - how might these be systematically altered to increase the proportion of women who achieve healthy weight gain during pregnancy? We need to support initiatives, such as Baby Friendly Hospitals, that support and encourage breastfeeding. We need to apply systems science methodologies to simulate the impact of various policy decisions and how they play out over time before actually putting them into practice [38]. Once effective interventions are identified, we will need to boldly shape policies to put them in place for all women. Insurers might help make them sustainable by covering obesity prevention and treatment services before they are associated with type 2 diabetes or high blood pressure.

Beyond the prenatal period, early childhood is another critical period of development that should be targeted for obesity prevention. Children's lives are embedded in the context of their family. The home environment provided by parents is the setting in which genetic predispositions for becoming overweight or obese are expressed [39]. We know families play a critical role in child weight trajectories. We do not know the relative influence of parenting parameters on child weight. We do not understand the underlying mechanisms that are influencing weight trajectories, although we know that parental modeling alone cannot explain child weight. While family-based approaches to obesity prevention are deemed necessary in pediatric obesity treatment, family theories are conspicuously missing from our research and practice [40]. We need to apply systems science methodologies to understand the effects of family dynamics on child weight and to identify key ingredients and leverage points, and how they change over time.

To date, there are very few pediatric obesity programs that successfully prevent or decrease obesity $[41,42]$. The most successful programs are comprehensive, and include: parenting skills training (e.g., learning to set limits, role model, and use positive reinforcement), behavior modification training (e.g., self-monitoring of diet and physical activity, goal setting, modeling, and limit setting), promotion of physical activity and nutrition education [43].

Successful programs are time-consuming, costly, and difficult to maintain. The majority of programs cannot easily be incorporated into standard pediatric health promotion activities (e.g., well child visits), daily school activities, much less family routines. To advance care, we need to promote policy, system and environmental changes, to make it possible for families to choose a default healthy lifestyle. But, in the absence of a sweeping policy agenda to create child-friendly, health-promoting communities, what are families and providers caring for children to do today?

\section{What are families and providers to do?}

Despite the overwhelming difficulty for parents and families to make lifestyle changes to promote their children's health and well-being, there may be some "simple" answers. Recent literature has highlighted that "simple" changes can have a profound effect on children's weight status. Most noticeably, limiting 
computer/TV/video screen-time can significantly influence children's risk for becoming overweight [44-46]. By just turning off the television, parents are encouraging their children to be more active. Household routines around meal-times can also impact children's risk for obesity. Health care providers need to encourage families to take the time to sit down together for a meal $[44,47,48]$. Establishing sleep routines, early in childhood, is another avenue for parents to promote the health and well-being of their children [44,47]. These "simple" changes can have a significant impact on children's weight trajectory, and thus their risk for becoming overweight and obese.

Changing the focus of interactions from preventing and treating obesity to promoting health and well-being, may help families be more inclined to work with their health care providers. Parents may be more open to modifying behaviors and instituting small changes that they see as generally benefitting their child's school performance, happiness or social popularity. Focus on improving success in life could be a "stealth" intervention to prevent obesity.

We know family norms reinforce behaviors. Parents might ask: «What, when, and how much do family members eat?», «How physically active are family members?», «How much support do family members offer each other?», "Are undue burdens placed on individuals (e.g., parent expected to cook different meals for family members with different preferences; child expected to resist unhealthy snacks that are readily available)?».

Providers can advise families «to integrate physical activity every day in every way» and «to make water the beverage of choice», and they can play a enormous role in bringing about systems change by jumping into the public policy debate (locally and nationally).

\section{Summary}

While we may not understand why our anti-obesity interventions typically fail, we should no longer be surprised by this fact. A complex system of obesogenic forces is sustaining the epidemic in ways we still don't understand. What is needed is a comprehensive coordination of efforts, guided by systems science, and backed by bold, evidence-based policy making. This approach holds the greatest promise of dramatically improving the public's health and being sustainable for the generations to come.

\section{Acknowledgements}

S.B. Gesell was supported by the Eunice Kennedy Shriver National Institute of Child Health and Human Development (NICHD) grant number K23 HD064700. The content is solely the responsibility of the authors and does not necessarily represent the official views of the National Institutes of Health or the NICHD.

\section{References}

1. World Health Organization. Obesity and Overweight [Fact Sheet No 311], 2012. Available at: http://www.who.int/mediacentre/factsheets/fs311/en/index.html [Last accessed October 1, 2012]

2. Food and Agriculture Organization of the United Nations, World Food Program, the International Fund for Agricultural Development. The State of Food Insecurity in the World 2012. Rome: Food and Agriculture Organization of the United Nations, 2012

3. Ogden CL, Carroll MD, Kit BK, et al. Prevalence of obesity and trends in body mass index among US children and adolescents, 1999-2010. JAMA 2012; 307: 483-90; http://dx.doi.org/10.1001/ jama.2012.40 
4. Organisation for Economic Co-operation and Development. Obesity and the Economics of Prevention: OECD Publishing, 2010

5. Finkelstein EA, Trogdon JG, Cohen JW, et al. Annual medical spending attributable to obesity: payer-and service-specific estimates. Health Aff (Millwood) 2009; 28: w822-831; http://dx.doi. org/10.1377/hlthaff.28.5.w822

6. Olshansky SJ, Passaro DJ, Hershow RC, et al. A potential decline in life expectancy in the United States in the 21st century. N Engl J Med 2005; 352: 1138-45; http://dx.doi.org/10.1056/NEJMsr043743

7. Institute of Medicine. Accelerating Progress in Obesity Prevention: Solving the Weight of the Nation. Washington, DC: The National Academics Press, 2012

8. Gortmaker SL, Swinburn BA, Levy D, et al. Changing the future of obesity: science, policy, and action. Lancet 2011; 378: 838-47; http://dx.doi.org/10.1016/S0140-6736(11)60815-5

9. Hammond RA. Complex systems modeling for obesity research. Prev Chronic Dis 2009; 6: A97

10. Levy DT, Mabry PL, Wang YC, et al. Simulation models of obesity: a review of the literature and implications for research and policy. Obes Rev 2011; 12: 378-94; http://dx.doi.org/10.1111/ j.1467-789X.2010.00804.x

11. Nader PR, Huang TT, Gahagan S, et al. Next steps in obesity prevention: altering early life systems to support healthy parents, infants, and toddlers. Child Obes 2012; 8: 195-204

12. Chasan-Taber L, Schmidt MD, Pekow P, et al. Physical activity and gestational diabetes mellitus among Hispanic women. J Womens Health (Larchmt) 2008; 17: 999-1008; http://dx.doi. org/10.1089/jwh.2007.0560

13. Schieve LA, Cogswell ME, Scanlon KS. Trends in pregnancy weight gain within and outside ranges recommended by the Institute of Medicine in a WIC population. Matern Child Health J 1998; 2: 111-6; http://dx.doi.org/10.1023/A:1022992823185

14. Finer LB, Zolna MR. Unintended pregnancy in the United States: incidence and disparities, 2006. Contraception 2011; 84: 478-85; http://dx.doi.org/10.1016/j.contraception.2011.07.013

15. Mamun AA, O'Callaghan M, Callaway L, et al. Associations of gestational weight gain with offspring body mass index and blood pressure at 21 years of age: evidence from a birth cohort study. Circulation 2009; 119: 1720-7; http://dx.doi.org/10.1161/CIRCULATIONAHA.108.813436

16. Moreira P, Padez C, Mourao-Carvalhal I, et al. Maternal weight gain during pregnancy and overweight in Portuguese children. Int J Obes (Lond) 2007; 31: 608-14; http://dx.doi.org/10.1038/ sj.ijo.0803582

17. Wrotniak BH, Shults J, Butts S, et al. Gestational weight gain and risk of overweight in the offspring at age $7 \mathrm{y}$ in a multicenter, multiethnic cohort study. Am J Clin Nutr 2008; 87: 1818-24

18. Armitage JA, Poston L, Taylor PD. Developmental origins of obesity and the metabolic syndrome: the role of maternal obesity. Front Horm Res 2008; 36: 73-84; http://dx.doi.org/10.1159/000115355

19. Botton J, Heude B, Maccario J, et al; FLVS Study Group. Postnatal weight and height growth velocities at different ages between birth and $5 \mathrm{y}$ and body composition in adolescent boys and girls. Am J Clin Nutr 2008; 87: 1760-8

20. Levin BE. The obesity epidemic: metabolic imprinting on genetically susceptible neural circuits. Obes Res 2000; 8: 342-7; http://dx.doi.org/10.1038/oby.2000.41

21. Simmons R. Perinatal programming of obesity. Semin Perinatol 2008; 32: 371-4; http://dx.doi. org/10.1053/j.semperi.2008.08.004

22. Barker DJ. The fetal and infant origins of disease. Eur J Clin Invest 1995; 25: 457-63; http://dx.doi. org/10.1111/j.1365-2362.1995.tb01730.x

23. Blass EM. Biological and environmental determinants of childhood obesity. Nutr Clin Care 2003; 6: $13-9$

24. Gillman MW, Kleinman K. Antecedents of obesity - analysis, interpretation, and use of longitudinal data. Am J Epidemiol 2007; 166: 14-6; http://dx.doi.org/10.1093/aje/kwm101 
25. Ness AR. The Avon Longitudinal Study of Parents and Children (ALSPAC)--a resource for the study of the environmental determinants of childhood obesity. Eur J Endocrinol 2004; 151 (Suppl 3): U141-149; http://dx.doi.org/10.1530/eje.0.151U141

26. Reidpath DD, Burns C, Garrard J, et al. An ecological study of the relationship between social and environmental determinants of obesity. Health Place 2002; 8: 141-5; http://dx.doi.org/10.1016/ S1353-8292(01)00028-4

27. van der Horst $\mathrm{K}$, Oenema A, van de Looij-Jansen $\mathrm{P}$, et al. The ENDORSE study: research into environmental determinants of obesity related behaviors in Rotterdam schoolchildren. BMC Public Health 2008; 8: 142; http://dx.doi.org/10.1186/1471-2458-8-142

28. Gore SA, Brown DM, West DS. The role of postpartum weight retention in obesity among women: a review of the evidence. Ann Behav Med 2003; 26: 149-59; http://dx.doi.org/10.1207/ S15324796ABM2602_07

29. Kinnunen TI, Pasanen M, Aittasalo M, et al. Reducing postpartum weight retention--a pilot trial in primary health care. Nutr J 2007; 6: 21; http://dx.doi.org/10.1186/1475-2891-6-21

30. Lumley J, Oliver SS, Chamberlain C, et al. Interventions for promoting smoking cessation during pregnancy. Cochrane Database Syst Rev 2004: CD001055

31. Stade BC, Bailey C, Dzendoletas D, et al. Psychological and/or educational interventions for reducing alcohol consumption in pregnant women and women planning pregnancy. Cochrane Database Syst Rev 2009: CD004228

32. Institute of Medicine, National Research Council. Weight Gain During Pregnancy: Reexamining the Guidelines. Washington, DC: The National Academics Press, 2009

33. Viswanathan M, Siega-Riz AM, Moos M-K, et al. Outcomes of Maternal Weight Gain. Rockville, MD: Agency for Healthcare Research and Quality (US); May 2008

34. Oteng-Ntim E, Varma R, Croker H, et al. Lifestyle interventions for overweight and obese pregnant women to improve pregnancy outcome: systematic review and meta-analysis. BMC Med 2012; 10: 47; http://dx.doi.org/10.1186/1741-7015-10-47

35. Streuling I, Beyerlein A, von Kries R. Can gestational weight gain be modified by increasing physical activity and diet counseling? A meta-analysis of interventional trials. Am J Clin Nutr 2010; 92: 678-87; http://dx.doi.org/10.3945/ajcn.2010.29363

36. Claesson IM, Josefsson A, Cedergren M, et al. Consumer satisfaction with a weight-gain intervention programme for obese pregnant women. Midwifery 2008; 24: 163-7; http://dx.doi. org/10.1016/j.midw.2006.10.007

37. Wolff S, Legarth J, Vangsgaard K, et al. A randomized trial of the effects of dietary counseling on gestational weight gain and glucose metabolism in obese pregnant women. Int J Obes (Lond) 2008; 32: 495-501; http://dx.doi.org/10.1038/sj.ijo.0803710

38. Sterman JD. Learning from evidence in a complex world. Am J Public Health 2006; 96: 505-14; http://dx.doi.org/10.2105/AJPH.2005.066043

39. Birch LL, Fisher JO. Development of eating behaviors among children and adolescents. Pediatrics 1998; 101: 539-49

40. Skelton JA, Buehler C, Irby MB, et al. Where are family theories in family-based obesity treatment?: conceptualizing the study of families in pediatric weight management. Int J Obes (Lond) 2012; 36: 891-900; http://dx.doi.org/10.1038/ijo.2012.56

41. Summerbell CD, Waters E, Edmunds LD, et al. Interventions for preventing obesity in children. Cochrane Database Syst Rev 2005: CD001871

42. Thomas H. Obesity prevention programs for children and youth: why are their results so modest? Health Educ Res 2006; 21: 783-95; http://dx.doi.org/10.1093/her/cyl143

43. American Dietetic Association. Position of the American Dietetic Association: individual-, family-, school-, and community-based interventions for pediatric overweight. J Am Diet Assoc 2006; 106: 925-45; http://dx.doi.org/10.1016/j.jada.2006.03.001 
44. Anderson SE, Whitaker RC. Household routines and obesity in US preschool-aged children. Pediatrics 2010; 125: 420-8; http://dx.doi.org/10.1542/peds.2009-0417

45. Mendoza JA, Zimmerman FJ, Christakis DA. Television viewing, computer use, obesity, and adiposity in US preschool children. Int J Behav Nutr Phys Act 2007; 4: 44; http://dx.doi. org/10.1186/1479-5868-4-44

46. Plachta-Danielzik S, Kehden B, Landsberg B, et al. Attributable risks for childhood overweight: evidence for limited effectiveness of prevention. Pediatrics 2012; 130: e865-871; http://dx.doi. org/10.1542/peds.2011-3296

47. Dattilo AM, Birch L, Krebs NF, et al. Need for early interventions in the prevention of pediatric overweight: a review and upcoming directions. J Obes 2012; 1-18; http://dx.doi. org/10.1155/2012/123023

48. Lehto R, Ray C, Roos E. Longitudinal associations between family characteristics and measures of childhood obesity. Int J Public Health 2012; 57: 495-503; http://dx.doi.org/10.1007/ s00038-011-0281-5 